\title{
Obesity in Hemodialysis Patients
}

\author{
Imen Gorsane, Madiha Mahfoudhi*, Mounira El Euch, Fathi Younsi, \\ Taieb Ben Abdallah \\ Internal Medicine A Department, Charles Nicolle Hospital, Tunis, Tunisia \\ Email: ${ }^{*}$ madiha_mahfoudhi@yahoo.fr
}

Received 19 May 2015; accepted 14 September 2015; published 17 September 2015

Copyright (C) 2015 by authors and Scientific Research Publishing Inc.

This work is licensed under the Creative Commons Attribution International License (CC BY).

http://creativecommons.org/licenses/by/4.0/

(c) (i) Open Access

\section{Abstract}

Obesity is a cardiovascular risk factor in the general population. However, obesity on hemodialysis is associated with better survival. The aim of this study is to determine the prevalence of obesity in our chronic hemodialysis population and to specify the different cardiovascular complications. It is a cross-sectional study with 120 patients older than 18 years on hemodialysis. Abdominal obesity was defined as waist circumference $>94 \mathrm{~cm}$ in men and $>80 \mathrm{~cm}$ in women. The following were analyzed: socioeconomic and demographic parameters, lifestyle, initial renal disease, duration of hemodialysis, food consumption and body mass index (BMI), biological parameters (C-reactive protein (CRP), albumin, lipid profiles, serum calcium, phosphorus, parathyroid hormone), comorbidities: Diabetes, hypertension, stroke, coronary artery disease. Twenty-four patients had a BMI $>25$. The prevalence of abdominal obesity was $20 \%$. The sex Ratio was 0.71 . The average age of our patients was 55.97 years [23 - 78 years]. Reduced physical activity was observed in $75 \%$ of patients. Duration in hemodialysis was 79 months. Hemoglobin $(\mathrm{Hb})$ average was $8.9 \mathrm{~g} / \mathrm{dl}$, serum calcium was $2.25 \mathrm{mmol} / \mathrm{l}$, serum phosphorus was $1.7 \mathrm{mmol} / \mathrm{l}$, parathyroid hormone (PTH) was $412 \mathrm{pg} / \mathrm{ml}$, albuminemia was $30.7 \mathrm{~g} / \mathrm{l}$, total cholesterol was $3.75 \mathrm{mmol} / \mathrm{l}$ and CRP was $15 \mathrm{U} / \mathrm{l}$. Coronary artery disease was found in $20.8 \%$ of cases, stroke in $8.3 \%$ of cases, diabetes in $58.33 \%$ of cases and hypertension in $75 \%$ of cases. There was a high prevalence of abdominal obesity in hemodialysis patients. Obesity is recognized by its association with increased risk of cardiovascular disease and mortality. However in the paradoxical epidemiology, obesity becomes in chronic hemodialysis, a protective factor and is associated with better survival. Our study has a small population and cannot reach such a conclusion; further studies with larger numbers are needed to support this concept.

\section{Keywords}

Hemodialysis, Obesity, Metabolic Syndrome, Abdominal Fat

${ }^{*}$ Corresponding author. 


\section{Introduction}

A significant number of patients who undergo dialysis are overweight or obese [1] [2]. The presence of excess weight, especially visceral obesity contributes to the increased risk of metabolic and cardiovascular complications in patients with chronic kidney disease (CKD). The relationship between weight and outcome is complex among dialysis patients. The extra weight is usually associated with improved survival in this patient group [3].

\section{Patients and Methods}

It is a cross-sectional study in the Hemodialysis Unit of the Nephrology Department of Medicine A at the Charles Nicolle Hospital in Tunis in January 2015.

Inclusion criteria: Chronic hemodialysis patients older than 18 years with abdominal obesity defined as waist circumference $>94 \mathrm{~cm}$ in men and $>80 \mathrm{~cm}$ in women [4].

Exclusion criteria: Patients on hemodialysis for less than 3 months and patients with acute infection, or active neoplasia.

Twenty-four patients were selected for this study. For each patient were analyzed: socioeconomic and demographic parameters, lifestyle, initial renal disease, duration of $\mathrm{HD}$, food consumption and body mass index (BMI), biological parameters: C-reactive protein (CRP), albumin, lipid profiles, serum calcium, phosphorus, parathyroid hormone, comorbidities: Diabetes, hypertension (HT), stroke, coronary artery disease.

\section{Results}

The prevalence of abdominal obesity was $20 \%$. Twenty-four patients had a BMI $>25$. The mean waist circumference was $85 \mathrm{~cm}$ in women [80.5 - $95 \mathrm{~cm}$ ] and 98 in men [94.8 - $102 \mathrm{~cm}$ ]. The sex Ratio was 0.71 . The average age of our patients was 55.97 years [23 - 78 years]. Reduced physical activity was observed in $75 \%$ of patients. The prevalence of smoking was $55 \%$.

Duration in HD was 79 months. Seven patients had vascular nephropathy, 10 had diabetic nephropathy, 4 had chronic glomerular nephritis, 2 had chronic interstitial nephropathy and one patient had hereditary kidney disease (tuberous sclerosis of Bourneville). The average time between discovery of kidney failure and the onset of hemodialysis was 20 months.

Hemoglobin (Hb) average was $8.9 \mathrm{~g} / \mathrm{dl}[7.9$ - $9.8 \mathrm{~g} / \mathrm{dl}]$, serum calcium was $2.25 \mathrm{mmol} / \mathrm{l}$ [2.08 - $2.55 \mathrm{mmol} / \mathrm{l}$, serum phosphorus was $1.7 \mathrm{mmol} / \mathrm{l}$ [1.5 - $2.2 \mathrm{mmol} / \mathrm{l}]$. Secondary hyperparathyroidism was found in 12 patients (50\%) with a mean PTH of $412 \mathrm{pg} / \mathrm{ml}$.

The mean albuminimia was $30.7 \mathrm{~g} / \mathrm{l}[27-35 \mathrm{~g} / \mathrm{l}]$ and the mean total cholesterol was $3.75 \mathrm{mmol} / \mathrm{l}[2.9$ - 4 $\mathrm{mmol} / \mathrm{l}]$.

The inflammatory condition was evaluated using CRP as a marker of inflammation. Sixteen patients (66.6\%) had an inflammatory syndrome with a mean CRP of $15 \mathrm{U} / \mathrm{l}$.

Cardiovascular complications noted included coronary artery disease in $20.8 \%$ of cases, stroke in $8.3 \%$ of cases, diabetes in $58.33 \%$ of cases and HT in $75 \%$ of cases.

Demographic, clinical and biological characteristics were summarized in Table 1.

\section{Discussion}

In the general population, abdominal obesity is characterized by chronic low grade inflammation with increased serum inflammatory cytokine levels; it is considered to be a risk factor for atherosclerosis, cardiovascular disease, and increased mortality [5].

In obese dialysis patients, the nutritional status may be better, and obesity provides, in the short term, some protection against malnutrition and the associated morbidity. However, some studies suggest that mortality in the long term is directly correlated with excess weight and obesity, which indicates that fat represents a risk factor also in uremia [1] [3]. Observational studies in CKD patients as well as dialysis patients, link abdominal fat with inflammation, insulin resistance, hyperadipokinemia, dyslipidemia, oxidative stress [6]-[9] and cardiovascular events and mortality [10]-[12].

In patients requiring dialysis, disturbances in lipid and carbohydrate metabolism, which are common, have been associated with abdominal fat and may develop into metabolic syndrome (MetS) [13]. There are multiple 
Table 1. Demographic, clinical and biological characteristics.

\begin{tabular}{cc}
\hline Parameters & \\
\hline Age (years) & 55.97 \\
Smoking & $55 \%$ \\
Duration in hemodialysis (months) & 79 \\
Time between kidney failure and onset of HD (months) & 20 \\
Hemoglobin (g/dl) & 8.9 \\
Calcium (mmol/l) & 2.25 \\
Phosphorus (mmol/l) & 1.7 \\
PTH (pg/ml) & 412 \\
Albumin (mmol/l) & 30.7 \\
Cholesterol (mmol/l) & 3.75 \\
CRP (UI/L) & 15 \\
\hline
\end{tabular}

definitions of MetS, and the most current of MetS definitions is the National Cholesterol Education Program/ Adult Treatment Panel III [14]. It recognizes five components: hypertension, impaired fasting glucose, hypertriglyceridemia, abdominal obesity and low high-density lipoprotein cholesterol (HDL-C). The prevalence of MetS in chronic HD patients ranges from 40\% - 60\%; important relationship between MetS and the development of cardiovascular disease in chronic HD patients is found [15].

Recent evidence suggests that abdominal obesity play a role in peripheral arterial disease in dialysis patients [2]. Carotid artery intima media thickness is associated with waist circumference in peritoneal dialysis patients [16]. These vascular involvements are associated with morbidity in dialysis patients [17]. In our study, coronary artery disease was found in $20.8 \%$ of cases, stroke in $8.3 \%$ of cases, diabetes in $58.33 \%$ of cases and HT in $75 \%$ of cases.

Moreover, obesity does not necessarily imply good nutritional status. In patients with chronic kidney disease, there is a loss of muscle mass despite an excess of adipose tissue, which is a condition known as sarcopenic obesity [3] [6]. Malnutrition associated with obesity, including sarcopenic obesity, is the risk factor most closely correlated with morbidity and mortality both in dialysis patients and the general population [3].

BMI is inadequate as a measure of sarcopenic obesity since it cannot define neither muscle mass nor indicate the localization of the fat in the visceral compartment. Other indices must be developed and validated in well performed clinical trials to identify fat localization and the presence of sarcopenia [3].

Observational studies indicate improved survival in obese patients undergoing HD. Thus, it is hypothesized that dialysis patients at high risk of Protein-energy wasting (PEW) are protected by excess weight [18] [19]. The recent observations that waist circumference modifies the mortality risk associated with circulating triglycerides [20], leptin, and adiponectin [21], underscores the overall effect that abdominal obesity has on PEW.

Insulin resistance represents a major target for intervention in PEW. Alterations in glucose metabolism in the face of hyperinsulinemia and diminished tissue sensitivity to insulin are partially correctable by HD [18].

CKD patients have increased expression of proinflammatory cytokines and adipokines in abdominal subcutaneous tissue compared with healthy controls [22]-[24]. In our study, sixteen patients (66.6\%) had an inflammatory syndrome. This high rate is explained mainly by oxidative stress. In addition, this inflammation is responsible for the low $\mathrm{Hb}$ levels $(8.9 \mathrm{~g} / \mathrm{dl})$ in addition to the non-availability of recombinant erythropoietin in our hospital.

However, dialysis reverses uremia, residual metabolic derangements, inflammation, comorbid conditions, and the dialysis procedure itself may allow PEW to develop or worsen.

Leptin, and adiponectin, which were not dialyzable, were unfortunately not measured in our laboratory.

\section{Conclusion}

A good nutritional state is found in some obese dialysis patients, which probably accounts for the improved 
survival of the obese group. The results of the present study showed that there was a high prevalence of abdominal obesity in hemodialysis patients but cannot reach such a conclusion. Therefore, further studies are needed to clarify the prognostic effect of abdominal obesity in dialysis patients.

\section{Conflict of Interests}

The authors declare that there is no conflict of interests regarding the publication of this paper.

\section{References}

[1] Freitas, A.T., Vaz, I.M., Ferraz, S.F., Peixoto Mdo, R., Campos, M.I. and Fornés, N.S. (2013) Prevalence and Associated Factors with Abdominal Obesity in Hemodialysis Patients in Goiânia-GO. Jornal Brasileiro de Nefrologia, 35, 265-272. http://dx.doi.org/10.5935/0101-2800.20130045

[2] Yang, S.Y., Chiang, C.K., Hsu, S.P., Peng, Y.S., Pai, M.F., Ho, T.I., et al. (2007) Metabolic Syndrome Predicts Hospitalization in Hemodialysis Patients: A Prospective Asian Cohort Study. Blood Purification, 25, 252-259. http://dx.doi.org/10.1159/000101698

[3] Panzetta, G. and Abaterusso, C. (2010) Obesity in Dialysis and Reverse Epidemiology: True or False? Giornale Italiano di Nefrologia, 27, 629-638.

[4] Furman-Niedziejko, A., Rostoff, P., Rychlak, R., Golinska-Grzybala, K., Wilczynska-Golonka, M., Golonka, M., et al. (2014) Relationship between Abdominal Obesity, Platelet Blood Count and Mean Platelet Volume in Patients with Metabolic Syndrome. Folia Medica Cracoviensia, 54, 55-64.

[5] Berg, A.H. and Scherer, P.E. (2005) Adipose Tissue, Inflammation, and Cardiovascular Disease. Circulation Research, 96, 939-949. http://dx.doi.org/10.1161/01.RES.0000163635.62927.34

[6] Honda, H., Qureshi, A.R., Axelsson, J., Heimburger, O., Suliman, M.E., Barany, P., et al. (2007) Obese Sarcopenia in Patients with End-Stage Renal Disease Is Associated with Inflammation and Increased Mortality. The American Journal of Clinical Nutrition, 86, 633-638.

[7] Axelsson, J., Rashid Qureshi, A., Suliman, M.E., Honda, H., Pecoits-Filho, R., et al. (2004) Fat Mass as a Contributor to Inflammation in End-Stage Renal Disease. The American Journal of Clinical Nutrition, 80, 1222-1229.

[8] Gohda, T., Gotoh, H., Tanimoto, M., Sato, M., Io, H., Kaneko, K., et al. (2008) Relationship between Abdominal Fat Accumulation and Insulin Resistance in Hemodialysis Patients. Hypertension Research, 31, 83-88. http://dx.doi.org/10.1291/hypres.31.83

[9] Witasp, A., Carrero, J.J., Hammarqvist, F., Qureshi, A.R., Heimbürger, O., Schalling, M., et al. (2011) Expression of Osteoprotegerin in Human Fat Tissue; Implications for Chronic Kidney Disease. European Journal of Clinical Investigation, 4, 498-506. http://dx.doi.org/10.1111/j.1365-2362.2010.02432.x

[10] Kamimura, M.A., Carrero, J.J., Canziani, M.E., Watanabe, R., Lemos, M.M. and Cuppari, L. (2013) Visceral Obesity Assessed by Computed Tomography Predicts Cardiovascular Events in Chronic Kidney Disease Patients. Nutrition, Metabolism and Cardiovascular Diseases, 23, 891-897. http://dx.doi.org/10.1016/j.numecd.2012.06.004

[11] Postorino, M., Marino, C., Tripepi, G. and Zoccali, C., CREDIT (Calabria Registry of Dialysis and Transplantation) Working Group (2009) Abdominal Obesity and All-Cause and Cardiovascular Mortality in End-Stage Renal Disease. Journal of the American College of Cardiology, 53, 1265-1272. http://dx.doi.org/10.1016/j.jacc.2008.12.040

[12] Wu, C.C., Liou, H.H., Su, P.F., Chang, M.Y., Wang, H.H., Chen, M.J., et al. (2011) Abdominal Obesity Is the Most Significant Metabolic Syndrome Component Predictive of Cardiovascular Events in Chronic Hemodialysis Patients. Nephrology Dialysis Transplantation, 26, 3689-3695. http://dx.doi.org/10.1093/ndt/gfr057

[13] Huang, J.W., Yang, C.Y., Wu, H.Y., Liu, K.L., Su, C.T., Wu, C.K., et al. (2013) Metabolic Syndrome and Abdominal Fat Are Associated with Inflammation, But Not with Clinical Outcomes, in Peritoneal Dialysis Patients. Cardiovascular Diabetology, 12, 86. http://dx.doi.org/10.1186/1475-2840-12-86

[14] Expert Panel on Detection, Evaluation, and Treatment of High Blood Cholesterol in Adults (2001) Executive Summary of the Third Report of the National Cholesterol Education Program (NCEP) Expert Panel on Detection, Evaluation, and Treatment of High Blood Cholesterol In Adults (Adult Treatment Panel III). JAMA, 285, 2486-2497. http://dx.doi.org/10.1001/jama.285.19.2486

[15] Ucar, E., Huzmeli, C., Guven, O., Savas, N., Gullu, M., Asilyoruk, S., et al. (2009) Frequency of Metabolic Syndrome among Hemodialysis Patients According to NCEP-ATP III and IDF Definitions. Ren Fail, 31, 221-228. http://dx.doi.org/10.1080/08860220802669883

[16] Asicioglu, E., Kahveci, A., Arikan, H., Koc, M., Tuglular, S. and Ozener, C.I. (2013) Waist Circumference Is Associated with Carotid Intima Media Thickness in Peritoneal Dialysis Patients. International Urology and Nephrology, 45, 1437 1443. http://dx.doi.org/10.1007/s11255-013-0427-x 
[17] Hung, P.H., Tsai, H.B., Lin, C.H. and Hung, K.Y. (2013) Abdominal Obesity Is Associated with Peripheral Artery Disease in Hemodialysis Patients. PLoS One, 8, e67555. http://dx.doi.org/10.1371/journal.pone.0067555

[18] Carrero, J.J., Stenvinkel, P., Cuppari, L., Ikizler, T.A., Kalantar-Zadeh, K., Kaysen, G., et al. (2013) Etiology of the Protein-Energy Wasting Syndrome in Chronic Kidney Disease: A Consensus Statement from the International Society of Renal Nutrition and Metabolism (ISRNM). Journal of Renal Nutrition, 23, 77-90. http://dx.doi.org/10.1053/j.jrn.2013.01.001

[19] Fouque, D., Kalantar-Zadeh, K., Kopple, J., Cano, N., Chauveau, P., Cuppari, L., et al. (2008) A Proposed Nomenclature and Diagnostic Criteria for Protein-Energy Wasting in Acute and Chronic Kidney Disease. Kidney International, 73, 391-398. http://dx.doi.org/10.1038/sj.ki.5002585

[20] Postorino, M., Marino, C., Tripepi, G. and Zoccali, C. (2011) Abdominal Obesity Modifies the Risk of Hypertriglyceridemia for All-Cause and Cardiovascular Mortality in Hemodialysis Patients. Kidney International, 79, 765-772. http://dx.doi.org/10.1038/ki.2010.493

[21] Zoccali, C., Postorino, M., Marino, C., Pizzini, P., Cutrupi, S. and Tripepi, G. (2011) Waist Circumference Modifies the Relationship between the Adipose Tissue Cytokines Leptin and Adiponectin and All-Cause and Cardiovascular Mortality in Haemodialysis Patients. Journal of Internal Medicine, 269, 172-181. http://dx.doi.org/10.1111/j.1365-2796.2010.02288.x

[22] Carrero, J.J., Cordeiro, A.C., Lindholm, B. and Stenvinkel, P. (2010) The Emerging Pleiotrophic Role of Adipokines in the Uremic Phenotype. Current Opinion in Nephrology \& Hypertension, 19, 37-42. http://dx.doi.org/10.1097/MNH.0b013e328332fc2b

[23] Witasp, A., Carrero, J.J., Heimbürger, O., Lindholm, B., Hammarqvist, F., Stenvinkel, P., et al. (2011) Increased Expression of Pro-Inflammatory Genes in Abdominal Subcutaneous Fat in Advanced Chronic Kidney Disease Patients. Journal of Internal Medicine, 269, 410-419. http://dx.doi.org/10.1111/j.1365-2796.2010.02293.x

[24] Carvalho, L.K., Silva, M.I.B., da Silva Vale, B., Bregman, R., Martucci, R.B., Carrero, J.J. and Avesani, C.M. (2012) Annual Variation in Body Fat Is Associated with Systemic Inflammation in Chronic Kidney Disease Patients Stages 3 and 4: A Longitudinal Study. Nephrology Dialysis Transplantation, 27, 1423-1428.

http://dx.doi.org/10.1093/ndt/gfr450

\section{Abbreviations}

Body mass index: BMI

C-reactive protein: CRP

Chronic kidney disease: CKD

Hemodialysis: HD

Hemoglobin: $\mathrm{Hb}$

Hypertension: HT

Metabolic syndrome: MetS

Parathyroid hormone: PTH

Protein-energy wasting: PEW 